\title{
Research of air noise levels created in diesel shunting locomotive`s cabin
}

\author{
Ivan A. Yaitskov \\ Scientific-Research Department \\ Rostov State Transport University \\ Rostov-on-Don, Russia \\ yia@rgups.ru
}

\begin{abstract}
The designing and creating rail vehicles with increased power and performance, in the design decisions of which the vibroactive working parts are widely used, are inevitably accompanied by an increase in vibroacoustic characteristics. It leads to the deterioration of the working conditions for locomotive crews as well as acoustic and vibration effects on the residential area during the operation of the locomotives. The main source of the vibroacoustic impact of the locomotives is the internal combustion engine installed with the driver's cab on the load-bearing frame. The aim of the research, the obtained results of which are presented in this article, consisted of the theoretical description of sound pressure levels in the locomotive drivers' cabs with influence of the air noise. For developing practical recommendations, the dependencies have been obtained that can select the materials for reducing possible noise to sanitary standards.
\end{abstract}

Keywords- noise; vibration, cabin; internal combustion engines, diesel shunting locomotives

\section{INTRODUCTION}

The researches aim at a theoretical description of the processes of the excitation of vibration and noise emissions at workplaces of the locomotive brigades are relevant and have great scientific, engineering and socio-economic importance. In addition, it should be noted that the tiredness of drivers was primarily determined by the impact of vibration and acoustic characteristics that had negative affect on safety of traffic transport vehicles.

As opposed to well-known researches of the noise generation in cabs of the locomotives and diesel shunting locomotives [1-16], the model of the noise generation process is substantially pointed for each elements of the internal combustion engine' sides towards each fifth of the cab enclosure (with the exception of the floor), is located at different distances and has different diffraction coefficients.

\section{OBJECTS AND METHODS OF RESEARCH}

The design features of the vibroacoustic system of the diesel shunting locomotives are:

- A crane is installed on the roof of the cab of the locomotive (Fig. 1), the drive of which is a source of the sound radiation and vibrations.
- The diesel shunting locomotive as the loading transport locomotive LTL-6 (Fig. 2) is equipped with a removable workshop with a set of machines and tools which create a sound field in a closed volume with rigid enclosing walls.

- The cabins of the diesel shunting locomotives have a larger glazing area than the locomotives.

These features must be taken into account when calculating the air noise component at the engine operator's workplaces.

As research objects, the loading transport locomotive LTL6 and LTL-4 were chosen; the loading transport locomotive LTL-6 is equipped with two cabs (Fig. 2).

On the approach developing basement [1] for the cabs of the track and road-building machines, the dependence of the sound pressure levels created by the i-th enclosing element of the cabin on the driver's workplace was obtained:

$$
\begin{aligned}
& L_{c a b i}=L_{P_{\Sigma}}+10 \lg \sum_{1}^{5} \operatorname{arctg} \frac{l_{i} l_{i}}{2 R_{i} \sqrt{4 R_{i}^{2}+l_{i}^{2}+l_{i}^{2}}}+ \\
& \text { +10lg1510lg15Sißisik } \\
& \text { 100,1Spik+10g16aifsikßiScab+27, (1) }
\end{aligned}
$$

where $L_{P_{\Sigma}}-$ the noise levels near the i-th element of the enclosure ice, $\mathrm{dB}$;

$R_{i}$-the distance from the i-th element of the enclosure ice to the calculated point, $\mathrm{m}$;

$l_{i} l_{i}$-dimensions of the corresponding side element ice, $\mathrm{m}$;

$S_{i k}$-the area of the corresponding element of the cabin of the locomotive, $\mathrm{m}^{2}$;

$S p_{i k}$-soundproofing of the corresponding element of the cabin of the locomotive, $\mathrm{dB}$;

$S_{c a b}$-the area of the inner surface of the cabin, $\mathrm{m}^{2}$;

$\alpha_{i}^{f} \quad$-the frequency-dependent coefficients of sound absorption of the cabin of the locomotive. 


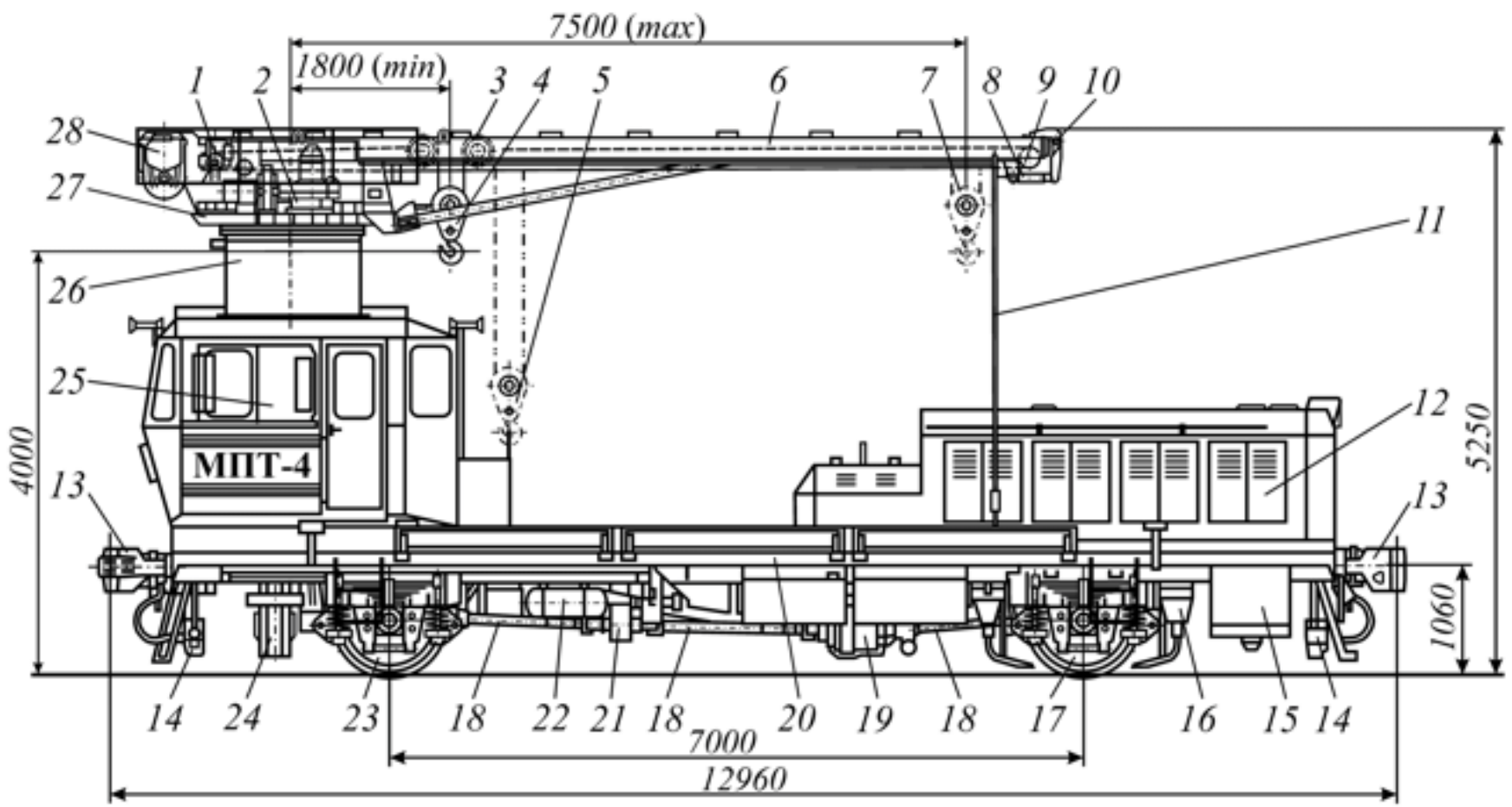

Fig. 1. The configuration of the loading transport locomotive LTL-4:

1 - the pulling winch; 2 - the jib swing drive; 3-the loading trolley; 4, 7 - the extreme positions of the hook block; 5 - the transport position of the hook block; 6 the jib of the crane; 8 - the warping; 9 - the bypass block; 10 - the load limiter; 11 - the transport spacers; 12 - the diesel generator; 13 - the automatic couplers; 14 - the coils of CLUB-OC; 15 - the fuel tank; 16 - the sandbox; 17, 23 -the driven wheel pairs; 18 - the drive shafts; 19 - the universal hydraulic transmission LT-300; 20 - the platform; 21 - the intermediate support; 22 - the pneumatic system; 24 - the outriggers; 25 - the control foot-plate; 26 -the intermediate crane support; 27 - the base of the crane; 28 - the cargo winch.

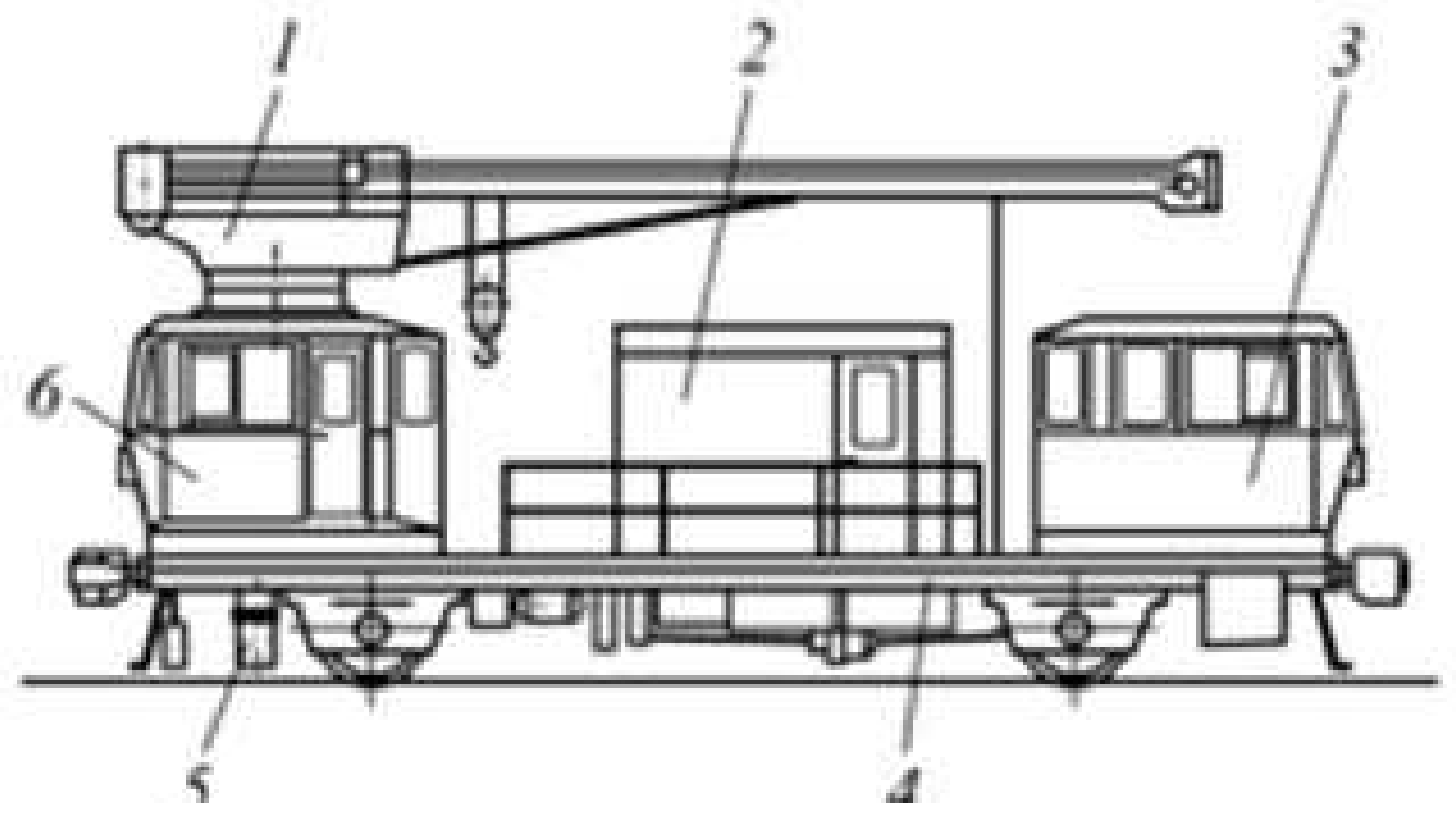

Fig. 2. The loading transport locomotive LTL-6 (Overview):

1 - the jib of the crane; 2 - the locksmith's workshop; 3 - the cabin for transportation of mechanized brigades; 4 - the platform of the locomotive; 5 - outriggers; 6 - the control foot-plate 
The sound energy, radiated by the internal combustion engine`s sides of the vehicle, passes through the sides and also affects the five elements of the locomotive cabin.

The dependence for the calculation of the noise levels in the cabin of a locomotive is reduced to:

$$
\begin{aligned}
& L_{k i}^{2}= \\
& L_{P_{\Sigma}}+10 \lg \left(0,14+\frac{1-\overline{\alpha_{0}}}{\overline{\alpha_{0}} S_{0}}\right)+ \\
& +10 \lg \sum_{1}^{5} \frac{s_{g i}}{2 R_{g i} \sqrt{4 R_{g i}^{2}+l_{g i}^{2}+l_{g i}^{2}}}+10 \lg 10 \lg \sum_{1}^{5} \frac{s_{g i} \beta_{g i}}{S_{g i} 10^{0,1 S I_{\mathrm{o} i}}}+ \\
& +10 \lg 10 \sum_{1}^{5} \frac{S_{k i} \beta_{i}}{S_{k i} 10^{0,1 S p_{k i}}}+10 \lg \frac{\sum_{1}^{6} \alpha_{i}^{f} S_{k i}}{S_{k}}+36
\end{aligned}
$$

where $\overline{\alpha_{0}}$-the average coefficient of sound absorption of the fence;

$S_{0}$-the area of the internal surface of the hood, $\mathrm{m}^{2}$;

$g$ - the index referring to the elements of the engine;

$S I_{\mathrm{o} i}$ - the sound insulation of the side, $\mathrm{dB}$.

The sound pressure levels created in the cabin by the sound emission of the ice and the outputs are determined by the formula:

$$
\begin{aligned}
& L_{\text {pres }}=L_{w_{r e l}}-20 \lg R_{r e l}-10 \lg \frac{\sum_{1}^{5} s_{c a b}}{\sum_{1}^{5} s_{c a b i} 10^{-0,1}\left(s p_{c a b i}+t_{g i}^{2}\right)}+ \\
& +10 \lg \frac{\sum_{1}^{6} s_{c a b i} f_{i k}}{S_{k}}+\Pi \mathrm{H}-\beta_{r e l}-5
\end{aligned}
$$

where $L_{w_{r e l}}-$ the sound power levels of the ice`s, dB; $\mathrm{m}$;

$R_{r e l}$-the distance from the release to the calculated point,

$t_{g i}$-the addition to the soundproofing of the i-th element of the enclosure of the cabin depending on the location of the cabin in relation to the noise source:

$t_{g i}=0$, if the surface is located opposite the calculated point;

$t_{g i}=5 \mathrm{~dB}$ if the surface is located on the side or top hood elements;

$t_{g i}=8 \mathrm{~dB}$, if the surface is located on the rear elements of the back relatively to the calculated point) [4].

The characteristic feature of the cabs of the locomotives is the large surface area of the glazing elements. In this case, the area of the bearing structure of the cabin for applying soundabsorbing linings is significantly reduced. Therefore, it is advisable to theoretically substantiate the choice of materials with the required values of the sound absorption coefficients in the relevant frequency ranges, and use this data at the stage of designing the cabins.

For purposes of the cabs concerned, the expression of the noise levels at the engine operator's workplaces is obtained

$$
\begin{aligned}
& L=L_{w}+10 \lg \left(\frac{2}{\pi r^{2}}+4 \frac{1-1,3 \sum \alpha_{i}^{f} s_{i}}{\sum \alpha_{i}^{f} S_{i}}\right)=L_{w}+ \\
& +10 \lg \left|\sum\left(\alpha_{i}^{f} S_{i}\right)^{-1}-1,14\right|-20 \lg r+6
\end{aligned}
$$

From the obtained expression we find:

$$
\sum \alpha_{i}^{f} S_{i}=\left(10^{0,1\left(L-L_{w}\right)+2 \lg r-0,6}+1,14\right)^{-1} .
$$

In further calculations, it should be taken into account that the sound absorption coefficients of the glazing should be taken as constant values. In addition, the variation in the choice of the sound-absorbing floor material is limited, so the sound absorption coefficients can also be taken as constant values.

Consequently, the choice of the sound-absorbing materials is limited to the walls and the ceiling of the cabin. For these elements of the cabin, it is advisable to use the same materials.

We denote the areas of the corresponding elements and the sound absorption coefficients as follows:

- the glazing is $S_{1}, \alpha_{1}^{f}$;

- the floor is $S_{2}, \alpha_{2}^{f}$;

- the ceiling is $S_{2}, \alpha_{3}^{f}$;

- the sides of the cabin are $S_{4}, \alpha_{3}^{f}$.

In this case

$$
\sum \alpha_{i}^{f} S_{i}=S_{1}, \alpha_{1}^{f}+S_{2}, \alpha_{2}^{f}+S_{2}, \alpha_{3}^{f}+S_{4}, \alpha_{3}^{f} .
$$

Then the dependence takes the form:

$$
\begin{aligned}
& \alpha_{2}^{f}\left(S_{2}+S_{3}\right)=\left(10^{\left(0,1\left(L-L_{w}\right)+2 \lg r-0,6\right)}+1,14\right)^{-1}- \\
& -\left(S_{1}, \alpha_{1}^{f}+S_{2}, \alpha_{2}^{f}\right) .
\end{aligned}
$$

Consequently, the theoretical values of the required sound absorption coefficients are determined by the following formula:

$$
\begin{aligned}
& \alpha_{2}^{f}=\left(10^{\left(0,1\left(L-L_{w}\right)+2 \lg r-0,6\right)}+1,14\right)^{-1}\left(S_{2}+S_{3}\right)^{-1}- \\
& -\frac{S_{1}, \alpha_{1}^{f}+S_{2}, \alpha_{2}^{f}}{S_{2}+S_{3}} .
\end{aligned}
$$

\section{CONCLUSIONS}

The achieved dependencies make it possible to select the materials for reducing possible noise by the sound absorption method. It should be noted that if the sanitary standards of noise are not met, the increasing of the sound absorption significantly simplifies the design of soundproofing systems. 


\section{References}

[1] N.I. Ivanov, Fighting noise and vibrations on track and construction machines, 2nd ed., reworked and additional. Moscow: Transport, 1987, pp. 223.

[2] N.I. Ivanov, G.M. Kurtsev, Y.I. Elkin, "Noise in the cabins of the road construction machinery and tractors", SRW, Vol. 10, pp.10-15, 2005.

[3] N.I. Ivanov, B.A. Krishnevsky, "Analysis of the efficiency of soundproof cabins of self-propelled machines", Struggle against noise and harmful vibrations in construction, 1982, p.45-51.

[4] N.I. Ivanov, G.M. Kurtsev, A.E. Shashurin, "Calculation of the expected noise in the cabins when designing construction machines", New in Safety of Life and Ecology, ed. by N.I. Ivanov, SPb, 1996, pp. 586-596.

[5] I.A. Yaitskov, A.N. Chukarin, T.A. Finotchenko, "Theoretical Research of Noise and Vibration Spectra in Cabins of Locomotive and Diesel Shunting Locomotive", International Journal of Applied Engineering Research, Vol. 12, № 21, pp. 10724-10730, 2017.

[6] I.A. Yaitskov, "Theoretical study of the air component of the noise of power plants of transport vehicles", Internet-journal "Naukovedy" Vol. 9, №6, 2017.

[7] S.F. Podust, A.N. Chukarin, I.V. Boguslavsky, The basics of the vibroacoustic calculations of domestic electric locomotives. Rostov-onDon: Publishing center of DSTU, 2013, pp.157.

[8] Y.V. Pronnikov, "Modelling the structural component of noise in the cabs of rolling stock drivers", Vestnik of the RSTU, Rostov-on-Don, Vol. 3, pp.64-68, 2010.
[9] Y.V. Pronnikov, "On the calculation of the noise component in the cabs of the rolling stock drivers created by the vibration of the glazing elements", Transport, Security, Logistics, pp.8-14, October 2010 [International scientific and practical conf. Transport, Security, Logistics, p.418, 2010].

[10] Tholen P. "Schallschutbanham beim Einbau von Ver-brennungs motoren in Baumaschinen", Haus Techn, pp.56-58, 1970.

[11] A.N. Chukarin, "Theory and methods of the acoustic calculations and design of technological machines for machining", Monograph, Rostovon-Don: Publishing Center DSTU, 2005, pp.152.

[12] L.P. Borisov, D.R. Guzhas, Soundproofing in mechanical engineering, Moscow: Mechanical Engineering, 1990, pp.256.

[13] A.M. Kapustiansky, V.A. Herbert, V.S. Kaganov, B.Ch. Meskhi, "Dependence of the coefficient of the vibrational energy losses of thin steel plates as a function of thickness and frequency of oscillations", Designing technological machines, Issue 23, ed. by A.V. Pushcha, Moscow: SEI DPO "IUIAP", 2001, pp.22-24.

[14] G. Heimer, "Comparison of methods of protection against noise", Railways of the world, №5, pp. 24-31, 1999.

[15] G.V. Butakova, B.N. Melnikov, Noise in transport, ed. by V.E. Tolsky, G.V. Butakova, B.N. Melnikov, Moscow: Transport, 1995, pp.368.

[16] M.G. Dittrich, "Imagine railway noise source model, default source data and measurement protocol", EU-FP6 project IMAGINE report, TNO, 2005, p.44. 